until I was almost out of sight; then they would fly up to rejoin me. Sometimes when busy I would attempt to escape them and would be trying to corral scme wild cattle or steal a ride on a nervous colt, when here would come my gang for a closer look, and their flapping arrival generally turned my work to complete chaos. My wife once planted a whole row of strawberry plants, only to find that the Sandhills had pulled up every plant behir.d her. Their long bills are never still, probing constantly in the earth; snapping a luckless insect off a blade of grass with pinpoint accuracy, untying one's shoelaces or picking at the buttons on one's clothes. Try to dig a can of angle-worms for fish bait and they'll beat you to every worm. Grain the calves and the Sandhills are in the grain trough for their share. A curious thing is that they never let a plane go over without putting their heads back and uttering an ear-splitting protest. To see the Sandhills dance, on $\Leftarrow$ has only to toss a small stick intc the air before them. It is seized by the nearest crane who tosses it in turn and the bouncing game is on. One can't help liking the birds. I remember a very solemn and dignified cowboy of sixty-five who came to work for us. I was certain he thought us strange indeed, to have a bunch of cranes about. My fears vanished when I came around the corner of the barn one morning. There was the old cowboy in a ring with the cranes. Hat in hand, arms flapping, a big grin on his face, he was bounding a good three feet in the air with every jump.

\title{
Prairie Wildlife Habitat Meeting
}

The first meeting of wildlife biologists frcm Manitoba, Saskatchewan and Alberta was held in Regina on January 16 and 17 . The purpose of the meeting was to consider habitat requirements of furbearers, upland and migratory game birds.

To provide suitable habitat, the group favoured the acquisition of land by proviricial governments. It recommended that the wetlands inventory conducted by Ducks Unlimited in Saskatchewan be: (1) continued, (2) expanded to Alberta and Manitoba and (3) entered into on a co-operative basis by the provincial game branches and the Canadian Wildlife Service. The meeting favored the extended study of habitat requirements of upland game and the exchange of population data between provinces. Discussing the pheasant programme in Alberta, the group considered an experimental hen season for comparison with the traditional cock season and suggested that staggering the opening dates for resident and non-resident hunters for pheasants on the E.I.D. might ease hunting pressure.

With furbearers, the most urgent need in the southern prairies was considered to be a study of habitat requirements of muskrat and beaver.

Waterfowl management requirements include further knowledge of habitat requirements of each species, determination of size, distribution and methods of wateifowl harvest. The problem of depredation by waterfowl, and the question of crow and magpie predation were also discussed. A study of magpie predation on game bird nests is contemplated for Alberta in 1957, because it is felt that the present programme is not "controlling" the predators or increasing production of game birds.

Possibility of initiating an experimental study of Canada Goose nesting in the Quill Lake district was discussed. The project would be carried out by Ducks Unlimited and the Canadian Wildlife Service.

\section{COVER PHOTOS WANTED}

If you have photographs that would make suitable cover pictures for the Blue Jay, we should be very glad to have them. We want black and white photographs that are sharp and clear, of any wildlife subject taken in the Prairie Provinces. In size, prints submitted should be as large as, or larger than, the actual cover picture. All photographs will be returned.

With your picture, please send details of place and date taken and any other interesting or unusual particulars. 